\title{
COMO FICA A MEDIDA CAUTELAR PARA ANTECIPAÇÃO DE GARANTIA NO NCPC?
}

\author{
Adriana Passaro
}

\section{INTRODUÇÃO}

A pergunta que dá título a este capítulo é oportuna e a resposta passa por outras questões igualmente instigantes aos olhos dos estudiosos do processo civil e do direito tributário. O Novo Código de Processo Civil (NCPC) positivou a medida cautelar de caução prévia à execução fiscal, corrigindo a lacuna existente no Código de Processo Civil de 1973 (CPC/73)? Deixará de ser garantida ao contribuinte cujo débito ainda não foi ajuizado a isonomia em relação àqueles que já foram acionados judicialmente pelo fisco? Há uma solução processual para aqueles que se encontram no chamado "limbo processual tributário"?

Como se sabe, o processo administrativo fiscal garante ao contribuinte que impugnou tempestivamente a autuação lavrada contra si a suspensão da exigibilidade do crédito tributário, nos termos do art. 151, inciso III, ${ }^{1}$ do Código Tributário Nacional (CTN), assegurando-lhe, consequentemente, a certificação de regularidade fiscal e o pretendido exercício regular de suas atividades. Uma vez encerrada a discussão na esfera administrativa, com decisão desfavorável ao contribuinte, garante o mesmo art. 151 do CTN, em seu inciso II, ${ }^{2}$ que o crédito tri-

1 "Art. 151. Suspendem a exigibilidade do crédito tributário: [...] III - as reclamações e os recursos, nos termos das leis reguladoras do processo tributário administrativo; [...]."

2 "Il - o depósito do seu montante integral; [...]." 
butário também terá sua exigibilidade suspensa pelo depósito judicial do montante em discussão, de modo que, ajuizada a ação de cobrança pelo fisco e garantido o juízo, permanecerá o contribuinte em situação de regularidade fiscal.

Todavia, esse mesmo sistema tributário garante ao fisco um prazo de 5 anos para o exercício do seu direito de cobrança. Significa dizer que, após a constituição definitiva do crédito, quando do encerramento do processo administrativo, tem a Fazenda cinco anos para a propositura da ação de execução fiscal. Nesse período tem-se, portanto, de um lado crédito exigível e de outro execução fiscal ainda não ajuizada. Não há mais espaço para discussão em sede administrativa e não há lide instaurada judicialmente para o regular exercício de defesa por parte do contribuinte, mas o crédito tributário está em aberto. Resta assim caracterizado o limbo processual tributário a que nos referimos anteriormente.

Desse cenário nasceu a necessidade, ainda sob a égide do CPC/73, de encontrar uma forma de assegurar ao contribuinte o direito de garantir o débito ainda não ajuizado, possibilitando a emissão da conhecida Certidão Positiva com Efeitos de Negativa (CPEN), a fim de não prejudicar o exercício regular da atividade empresarial.

\section{MEDIDA CAUTELAR DE ANTECIPAÇÃO DE GARANTIA NO $\mathrm{CPC} / 73$}

A medida cautelar de caução ou de antecipação de garantia foi, por bastante tempo, a saída encontrada pelos contribuintes que estavam nesse limbo. Com fulcro nos art. 798 a 812 e $826^{3}$ do CPC/73, a medida cautelar proposta limitava-se a

3 "Art. 798. Além dos procedimentos cautelares específicos, que este Código regula no Capitulo II deste Livro, poderá o juiz determinar as medidas provisórias que julgar adequadas, quando houver fundado receio de que uma parte, antes do julgamento da lide, cause ao direito da outra lesão grave e de difícil reparação. Art. 799. No caso do artigo anterior, poderá o juiz, para evitar o dano, autorizar ou vedar a prática de determinados atos, ordenar a guarda judicial de pessoas e depósito de bens e impor a prestação de caução. Art. 800 . As medidas cautelares serão requeridas ao juiz da causa; e, quando preparatórias, ao juiz competente para conhecer da ação principal. Parágrafo único. Nos casos urgentes, se a causa estiver no tribunal, será competente o relator do recurso. Parágrafo único. Interposto o recurso, a medida cautelar será requerida diretamente ao tribunal. Art. 801. O requerente pleiteará a medida cautelar em petição escrita, que indicará: I - a autoridade judiciária, a que for dirigida; II - o nome, o estado civil, a profissão e a residência do requerente e do requerido; III - a lide e seu fundamento; IV - a exposição sumária do direito ameaçado e o receio da lesão; V - as provas que serão produzidas. Parágrafo único. Não se exigirá o requisito do no III 
requerer, tão somente, a garantia do débito não ajuizado e a expedição da certidão de regularidade fiscal, deixando a discussão sobre o mérito da exigência para os autos dos futuros embargos à execução fiscal.

senão quando a medida cautelar for requerida em procedimento preparatório. Art. 802 . O requerido será citado, qualquer que seja o procedimento cautelar, para, no prazo de 5 (cinco) dias, contestar o pedido, indicando as provas que pretende produzir. Parágrafo único. Conta-se o prazo, da juntada aos autos do mandado: I - de citação devidamente cumprido; II - da execução da medida cautelar, quando concedida liminarmente ou após justificação prévia. Art. 803. Não sendo contestado o pedido, presumir-se-ão aceitos pelo requerido, como verdadeiros, os fatos alegados pelo requerente (artigos 285 e 319); caso em que o juiz decidirá dentro em cinco (5) dias. Parágrafo único. Se o requerido contestar no prazo legal, o juiz designará audiência de instrução e julgamento. Art. 803. Não sendo contestado o pedido, presumir-se-ão aceitos pelo requerido, como verdadeiros, os fatos alegados pelo requerente (arts. 285 e 319); caso em que o juiz decidirá dentro em 5 (cinco) dias. Parágrafo único. Se o requerido contestar no prazo legal, o juiz designará audiência de instrução e julgamento, havendo prova a ser nela produzida. Art. 804. É lícito ao juiz conceder liminarmente ou após justificação prévia a medida cautelar, sem ouvir o réu, quando verificar que este, sendo citado, poderá torná-la ineficaz; caso em que determinará que o requerente preste caução real ou fidejussória de ressarcir os danos que o requerido possa vir a sofrer. Art. 805. A medida decretada poderá ser substituida pela prestação de caução, sempre que esta seja adequada e suficiente para evitar a lesão ou repará-la integralmente. Art. 806. Cabe à parte propor a ação, no prazo de 30 (trinta) dias, contados da data da efetivação da medida cautelar, quando esta for concedida em procedimento preparatório. Art. 807. As medidas cautelares conservam a sua eficácia no prazo do artigo antecedente e na pendência do processo principal; mas podem, a qualquer tempo, ser revogadas ou modificadas. Parágrafo único. Salvo decisão judicial em contrário, a medida cautelar conservará a eficácia durante o período de suspensão do processo. Art. 808. Cessa a eficácia da medida cautelar: I - se a parte não intentar a ação no prazo estabelecido no art. 806; || - se não for executada dentro de 30 (trinta) dias; III - se o juiz declarar extinto o processo principal, com ou sem julgamento do mérito. Parágrafo único. Se por qualquer motivo cessar a medida, é defeso à parte repetir o pedido, salvo por novo fundamento. Art. 809. Os autos do procedimento cautelar serão apensados aos do processo principal. Art. 810. O indeferimento da medida não obsta a que a parte intente a ação, nem influi no julgamento desta, salvo se o juiz, no procedimento cautelar, acolher a alegação de decadência ou de prescrição do direito do autor. Art. 811. Sem prejuízo do disposto no art. 16, o requerente do procedimento cautelar responde ao requerido pelo prejuízo que the causar a execução da medida: I - se a sentença no processo principal the for desfavorável; II - se, obtida liminarmente a medida no caso do art. 804 deste Código, não promover a citação do requerido dentro em 5 (cinco) dias; III - se ocorrer a cessação da eficácia da medida, em qualquer dos casos previstos no art. 808, deste Código; IV - se o juiz acolher, no procedimento cautelar, a alegação de decadência ou de prescrição do direito do autor (art. 810). Parágrafo único. A indenização será liquidada nos autos do procedimento cautelar. Art. 812. Aos procedimentos cautelares específicos, regulados no Capitulo seguinte, aplicam-se as disposições gerais deste Capítulo. [...] Art. 826. A caução pode ser real ou fidejussória." 
A entendida por parte da doutrina como medida cautelar satisfativa oferecia ao jurisdicionado não uma cautela, mas a própria tutela pretendida de forma antecipada, sob o argumento de que nada mais se buscava naquela medida acautelatória senão a garantia do débito pela antecipação da penhora que se realizaria em futura ação de cobrança, penhora esta que era, inclusive, transferida para a ação de execução fiscal quando de seu ajuizamento. Nem sempre pacífica nos tribunais, a matéria chegou ao Superior Tribunal de Justiça (STJ) e, em Recurso Representativo de Controvérsia, restou decidido, nos autos do Recurso Especial (Resp) n. 1.123.669/RS:

1. O contribuinte pode, após o vencimento da sua obrigação e antes da execução, garantir o juízo de forma antecipada, para o fim de obter certidão positiva com efeito de negativa.

2. Dispõe o artigo 206 do CTN que: "tem os mesmos efeitos previstos no artigo anterior a certidão de que conste a existência de créditos não vencidos, em curso de cobrança executiva em que tenha sido efetivada a penhora, ou cuja exigibilidade esteja suspensa". A caução oferecida pelo contribuinte, antes da propositura da execução fiscal é equiparável à penhora antecipada e viabiliza a certidão pretendida, desde que prestada em valor suficiente à garantia do juízo.

3. É viável a antecipação dos efeitos que seriam obtidos com a penhora no executivo fiscal, através de caução de eficácia semelhante. A percorrer-se entendimento diverso, o contribuinte que contra si tenha ajuizada ação de execução fiscal ostenta condição mais favorável do que aquele contra o qual o Fisco não se voltou judicialmente ainda.

4. Deveras, não pode ser imputado ao contribuinte solvente, isto é, aquele em condições de oferecer bens suficientes à garantia da dívida, prejuízo pela demora do Fisco em ajuizar a execução fiscal para a cobrança do débito tributário. Raciocínio inverso implicaria em que o contribuinte que contra si tenha ajuizada ação de execução fiscal ostenta condição mais favorável do que aquele contra o qual o Fisco ainda não se voltou judicialmente.

5. Mutatis mutandis o mecanismo assemelha-se ao previsto no revogado art. 570 do CPC, por força do qual era lícito ao devedor iniciar a execução. Isso porque as obrigações, como vínculos pessoais, nasceram para serem extintas pelo cumprimento, diferentemente dos direitos reais que visam à perpetuação da situação jurídica nele edificadas.

6. Outrossim, instigada a Fazenda pela caução oferecida, pode ela iniciar a execução, convertendo-se a garantia prestada por iniciativa do 
contribuinte na famigerada penhora que autoriza a expedição da certidão. (grifo nosso)

Concluiu a $1^{\text {a }}$ Seção do STJ que, a despeito da via cautelar utilizada, de cautela não se tratava, mas de medida satisfativa requerida como caução, capaz de antecipar os efeitos da penhora que será realizada em execução fiscal futura. Celeuma resolvida, os contribuintes sabiam, até então, o que fazer quando se encontravam no mencionado "limbo processual tributário".

Mas o cenário foi alterado com a extinção das medidas cautelares perpetrada pelo NCPC, vigente desde o dia 18 de março de 2016, que restringiu as tutelas provisórias a apenas dois grupos: (i) tutelas de urgência e (ii) tutelas de evidência. Segundo a professora Camila Vergueiro Catunda, esta assentada na ideia de evidência do direito e aquela fundada na ideia de perigo.

Para avançarmos neste estudo, é imprescindível que tratemos, ainda que de forma breve e apenas para contextualizar o tema, das tutelas provisórias no NCPC.

\section{AS TUTELAS PROVISÓRIAS NO NCPC}

Com o advento da Lei n. 13.105/2015 instituiu-se o NCPC, revogando o $\mathrm{CPC} / 73$ e promovendo alterações substanciais no processo civil, especialmente no tocante às tutelas provisórias.

Pretendeu o legislador, claramente, sanear omissões e complexidades existentes no diploma legal anterior, que tratava do tema sob o título "Processo cautelar" e visava assegurar, desde que verificada a presença dos requisitos, o resultado prático das providências cognitivas ou executivas aos litigantes. Mais que isso, normatizou o legislador a voz dos tribunais, vertendo em linguagem competente a jurisprudência pacífica. Atualmente, com respaldo nos art. 294 a $311^{4}$ do NCPC, os

4 “Art. 294. A tutela provisória pode fundamentar-se em urgência ou evidência. Parágrafo único. A tutela provisória de urgência, cautelar ou antecipada, pode ser concedida em caráter antecedente ou incidental. Art. 295. A tutela provisória requerida em caráter incidental independe do pagamento de custas. Art. 296. A tutela provisória conserva sua eficácia na pendência do processo, mas pode, a qualquer tempo, ser revogada ou modificada. Parágrafo único. Salvo decisão judicial em contrário, a tutela provisória conservará a eficácia durante o período de suspensão do processo. Art. 297. O juiz poderá determinar as medidas que considerar adequadas para efetivação da tutela provisória. Parágrafo único. A efetivação da tutela provisória observará as normas referentes ao cumprimento provisório da sentença, no que couber. Art. 298. Na decisão que conceder, negar, modificar ou revogar a tutela provisória, o juiz motivará seu convencimento de modo claro e preciso. Art. 299. A 
tutela provisória será requerida ao juízo da causa e, quando antecedente, ao juízo competente para conhecer do pedido principal. Parágrafo único. Ressalvada disposição especial, na ação de competência originária de tribunal e nos recursos a tutela provisória será requerida ao órgão jurisdicional competente para apreciar o mérito. Art. 303. Nos casos em que a urgência for contemporânea à propositura da ação, a petição inicial pode limitar-se ao requerimento da tutela antecipada e à indicação do pedido de tutela final, com a exposição da lide, do direito que se busca realizar e do perigo de dano ou do risco ao resultado útil do processo. $\S 1^{\circ}$ Concedida a tutela antecipada a que se refere o caput deste artigo: I - o autor deverá aditar a petição inicial, com a complementação de sua argumentação, a juntada de novos documentos e a confirmação do pedido de tutela final, em 15 (quinze) dias ou em outro prazo maior que o juiz fixar; II - o réu será citado e intimado para a audiência de conciliação ou de mediação na forma do art. 334; III - não havendo autocomposição, o prazo para contestação será contado na forma do art. 335 . $\S 2^{\circ}$ Não realizado o aditamento a que se refere o inciso I do $\S 1^{\circ}$ deste artigo, o processo será extinto sem resolução do mérito. $\S 3^{\circ} \mathrm{O}$ aditamento a que se refere o inciso I do $\S 1^{\circ}$ deste artigo dar-se-á nos mesmos autos, sem incidência de novas custas processuais. $\S 4^{\circ} \mathrm{Na}$ petição inicial a que se refere o caput deste artigo, o autor terá de indicar o valor da causa, que deve levar em consideração o pedido de tutela final. § $5^{\circ} \mathrm{O}$ autor indicará na petição inicial, ainda, que pretende valer-se do benefício previsto no caput deste artigo. § $6^{\circ}$ Caso entenda que não há elementos para a concessão de tutela antecipada, o órgão jurisdicional determinará a emenda da petição inicial em até 5 (cinco) dias, sob pena de ser indeferida e de o processo ser extinto sem resolução de mérito. Art. 304. A tutela antecipada, concedida nos termos do art. 303, torna-se estável se da decisão que a conceder não for interposto o respectivo recurso. $\S 1^{\circ}$ No caso previsto no caput, o processo será extinto. $\S 2^{\circ}$ Qualquer das partes poderá demandar a outra com o intuito de rever, reformar ou invalidar a tutela antecipada estabilizada nos termos do caput. $\S 3^{\circ} \mathrm{A}$ tutela antecipada conservará seus efeitos enquanto não revista, reformada ou invalidada por decisão de mérito proferida na ação de que trata o $\S 2^{\circ}$. $\S 4^{\circ}$ Qualquer das partes poderá requerer o desarquivamento dos autos em que foi concedida a medida, para instruir a petição inicial da ação a que se refere o $\S 2^{\circ}$, prevento o juízo em que a tutela antecipada foi concedida. $\S 5^{\circ} \mathrm{O}$ direito de rever, reformar ou invalidar a tutela antecipada, previsto no $\S 2^{\circ}$ deste artigo, extingue-se após 2 (dois) anos, contados da ciência da decisão que extinguiu o processo, nos termos do $\S 1^{\circ}$. $\S$ $6^{\circ} \mathrm{A}$ decisão que concede a tutela não fará coisa julgada, mas a estabilidade dos respectivos efeitos só será afastada por decisão que a revir, reformar ou invalidar, proferida em ação ajuizada por uma das partes, nos termos do $\S 2^{\circ}$ deste artigo. Art. 305. A petição inicial da ação que visa à prestação de tutela cautelar em caráter antecedente indicará a lide e seu fundamento, a exposição sumária do direito que se objetiva assegurar e o perigo de dano ou o risco ao resultado útil do processo. Parágrafo único. Caso entenda que o pedido a que se refere o caput tem natureza antecipada, o juiz observará o disposto no art. 303. Art. 306. O réu será citado para, no prazo de 5 (cinco) dias, contestar o pedido e indicar as provas que pretende produzir. Art. 307. Não sendo contestado o pedido, os fatos alegados pelo autor presumir-se-ão aceitos pelo réu como ocorridos, caso em que o juiz decidirá dentro de 5 (cinco) dias. Parágrafo único. Contestado o pedido no prazo legal, observar-se-á o procedimento comum. Art. 308. Efetivada a tutela cautelar, o pedido principal terá de ser formulado pelo autor no prazo de 30 (trinta) dias, caso em que será apresentado nos mesmos autos em que deduzido o pedido de tutela cautelar, não dependendo do adiantamento de novas custas processuais. $\S 1^{\circ} \mathrm{O}$ pedido principal pode ser formulado conjuntamente com o pedido de tutela cautelar. $\S 2^{\circ} \mathrm{A}$ causa de pedir poderá ser aditada no momento de formulação do pedido principal. 
litigantes podem requerer tutela provisória fundamentada em urgência ou evidência. As medidas cautelares nominadas, tal qual as conhecíamos, deixaram de existir.

Se por um lado os provimentos jurisdicionais definitivos dos processos de conhecimento e de execução são imediatos e satisfativos, as tutelas jurisdicionais provisórias, por serem deferidas mediante cognição sumária do magistrado, possuem eficácia imediata respaldada em urgência ou evidência, todavia podem ser modificadas ou confirmadas a qualquer tempo pela cognição exaustiva do juízo. São caracterizadas, portanto, pela sumariedade de cognição e precariedade.

Da leitura desses artigos extrai-se que a tutela provisória é gênero cujas espécies dividem-se em tutela provisória de urgência, subdividida em cautelar ou antecipada, e de evidência. Eis aí a primeira diferença percebida ao analisarmos o NCPC. Sob a égide do CPC/73, as tutelas provisórias, fossem elas cautelares ou antecipadas, precisavam ser requeridas, necessariamente, com fulcro na existência do perigo da demora e na fumaça do bom direito, ou ainda na verossimilhança da alegação e no fundado receio de dano. Cabia, portanto, ao jurisdicionado demonstrar o risco de dano a que estava sujeito, bem como sustentar a relevância jurídica de seus argumentos de defesa, requisitos imprescindíveis à concessão da tutela pretendida. Mas, como se verá adiante, o risco não é condição, na novel compilação, para a concessão da tutela de evidência.

$\S 3^{\circ}$ Apresentado o pedido principal, as partes serão intimadas para a audiência de conciliação ou de mediação, na forma do art. 334, por seus advogados ou pessoalmente, sem necessidade de nova citação do réu. $\S 4^{\circ}$ Não havendo autocomposição, o prazo para contestação será contado na forma do art. 335. Art. 309. Cessa a eficácia da tutela concedida em caráter antecedente, se: I - o autor não deduzir o pedido principal no prazo legal; II - não for efetivada dentro de 30 (trinta) dias; III - o juiz julgar improcedente o pedido principal formulado pelo autor ou extinguir o processo sem resolução de mérito. Parágrafo único. Se por qualquer motivo cessar a eficácia da tutela cautelar, é vedado à parte renovar o pedido, salvo sob novo fundamento. Art. 310. O indeferimento da tutela cautelar não obsta a que a parte formule o pedido principal, nem influi no julgamento desse, salvo se $\circ$ motivo do indeferimento for o reconhecimento de decadência ou de prescrição. Art. 311. A tutela da evidência será concedida, independentemente da demonstração de perigo de dano ou de risco ao resultado útil do processo, quando: I - ficar caracterizado o abuso do direito de defesa ou o manifesto propósito protelatório da parte; II - as alegações de fato puderem ser comprovadas apenas documentalmente e houver tese firmada em julgamento de casos repetitivos ou em súmula vinculante; III - se tratar de pedido reipersecutório fundado em prova documental adequada do contrato de depósito, caso em que será decretada a ordem de entrega do objeto custodiado, sob cominação de multa; IV - a petição inicial for instruida com prova documental suficiente dos fatos constitutivos do direito do autor, a que o réu não oponha prova capaz de gerar dúvida razoável. Parágrafo único. Nas hipóteses dos incisos II e III, o juiz poderá decidir liminarmente." 
Mas há outras mudanças tão ou mais relevantes apresentadas no novo livro dedicado às tutelas provisórias, como o fim da autonomia do processo cautelar, que falam de perto com o tema discutido neste trabalho. Estabelece o caput do art. 299 do NCPC que a tutela provisória será requerida ao juízo da causa, quando incidental, ou ao juízo competente para conhecer do pedido principal, na hipótese de pedido antecedente, não havendo de se falar mais, portanto, em processo cautelar autônomo. Concedida a tutela pretendida, caberá ao autor, ainda, o aditamento da petição inicial para a formulação do pedido de tutela definitiva, formulado nos mesmos autos, sob pena de extinção do processo sem resolução de mérito.

Tais dispositivos reforçam, nesse sentido, a precariedade das tutelas provisórias, que podem ser, a qualquer tempo, revogadas ou modificadas pelo juiz, consoante disposto nos novos art. 296 e 298 do NCPC. Qual deve ser, então, a via processual adotada pelo contribuinte, frente a todas essas mudanças, para garantia de seu débito previamente ao ajuizamento da execução fiscal, de modo que lhe seja assegurada a obtenção da certidão de regularidade fiscal, essencial à consecução da atividade empresarial?

Examinemos, especificamente, cada uma das novas tutelas provisórias.

\subsection{Tutela de urgência}

A prestação jurisdicional é função do Estado e, para obtê-la, os particulares e os órgãos públicos se valem do direito de ação para solucionar um litígio por meio da substituição da vontade das partes pela aplicação de norma geral e abstrata ao caso concreto. Ocorre que, em alguns casos, a espera pelo trâmite da ação pode acabar comprometendo o direito discutido e, em casos extremos, o provimento jurisdicional pode deixar de ser útil por perecimento do direito ou geração de dano irreparável, aquilo que a doutrina considera "dano marginal", causado pela morosidade processual. É nesse contexto que as tutelas de urgência se fazem imprescindíveis.

Observando o princípio da proporcionalidade, faz-se uma ponderação entre o tempo do trâmite normal da ação e os prejuízos ao direito pleiteado que poderão advir em razão desse tempo. Desse modo, considerando-se os fatores tempo e efetividade da prestação jurisdicional, está-se diante do periculum in mora, aquele já conhecido receio de que a demora na prolação da decisão judicial cause danos graves ou de difícil reparação ao jurisdicionado, exigindo, para se lhe evitar, a concessão da tutela de urgência. 
Nas palavras do professor Humberto Theodoro Júnior, ${ }^{5}$ são aquelas tutelas que visam

minimizar os danos decorrentes da excessiva demora na obtenção da prestação jurisdicional, quer seja ela imputável a fatores de natureza procedimental, ou mesmo extraprocessuais, relacionados à precária estrutura do Poder Judiciário, como a insuficiência de juízes e funcionários e a má distribuição de competências, entre outros.

Mas para tal concessão o perigo de dano deve ser concreto, atual e grave, isto é, um dano que não seja um mero temor do autor, mas efetivamente perceptível, cuja ocorrência seja iminente e o prejuízo possua intensidade relevante e, consequentemente, irreparável ou de difícil reparação. Na verdade, o que se vê ao analisar o capítulo das tutelas de urgência é que a sua concessão está condicionada, via de regra, ao binômio perigo de dano mais probabilidade do direito que se busca ver reconhecido, tal qual ocorria no $\mathrm{CPC} / 73$.

E note-se que os requisitos para a concessão da tutela de urgência, seja ela cautelar, seja ela antecipada, são exatamente os mesmos. Não obstaste, segundo critérios de conveniência, o legislador pátrio entendeu por bem estabelecer essa subdivisão, podendo ambas ser requeridas em caráter antecedente ou incidental.

\subsubsection{Tutela de urgência cautelar}

Na modalidade cautelar da tutela de urgência, o objetivo do autor não é a antecipação de um direito em si, mas a segurança de que futuramente haja a satisfação do direito pretendido, não sendo, desse modo, satisfativa.

Essa tutela possui natureza instrumental, uma vez que oferecerá subsídio para um processo de conhecimento ou execução. O autor deverá indicar a lide genericamente, expondo especialmente o motivo pelo qual pretende assegurar o direito em razão do perigo de dano e do risco ao resultado útil do processo. A lide principal deverá ser proposta no prazo de 30 dias nos mesmos autos, inovação do novo diploma legal que consolidou o processo sincrético, não havendo necessidade de que os autos sejam apensados.

5 THEODORO JÚNIOR, Humberto. Curso de Direito Processual Civil. 56. ed. Rio de Janeiro: Forense, 2015. p. 511. 
Vale destacar que a inércia do autor em deduzir o pedido principal no prazo legal faz cessar a eficácia da tutela cautelar concedida em caráter antecedente. Exceção é feita aos casos em que o autor tenha optado, como lhe faculta o $\ 1^{\circ}$ do art. 308, por expor o pedido de tutela cautelar simultaneamente ao principal, não havendo necessidade de reiterá-lo no prazo estabelecido no caput.

A tutela de urgência cautelar é, portanto, a situação na qual estão presentes o perigo na demora e a iminência de grave dano, e, segundo a classificação de Araken de Assis, ${ }^{6}$ faz-se necessária a presença de cinco características: "(a) situação cautelanda; (b) perigo de dano iminente; (c) temporariedade; (d) verossimilhança; (e) força mandamental da pretensão". Entende-se, portanto, que estará legitimado o autor a requerer a tutela cautelar para assegurar um direito quando estiver apto a comprovar em juízo seu interesse legítimo efetivamente ameaçado, cujo tempo da demanda prejudicará substancialmente, podendo gerar danos irreversíveis ou de difícil reversibilidade, demonstrando, outrossim, a probabilidade do direito invocado.

Será este o caminho do contribuinte no limbo processual tributário?

\subsubsection{Tutela de urgência antecipada}

A tutela de urgência antecipada, por sua vez, tem natureza jurídica mandamental. Nela o autor pretende que o poder judiciário ordene a prática de atos pleiteados nas ações de conhecimento declaratórias, constitutivas ou condenatórias, obtendo os efeitos da pretensão deduzida em juízo, isto é, os efeitos que teriam a própria sentença definitiva. É importante destacar que a referida tutela não se confunde com o julgamento antecipado do mérito, disposto no art. $355^{7}$ e seguintes do NCPC, uma vez que neste caso o que ocorre é o efetivo julgamento do pleito por meio de sentença e, na tutela antecipatória, se dá apenas a antecipação dos resultados da decisão de mérito provisoriamente por meio de uma decisão interlocutória.

Se o juiz entender pelo não atendimento dos requisitos para concessão da tutela, o autor será intimado para aditar a inicial no prazo de 5 dias, sob pena de extinção do processo sem resolução de mérito. Todavia, se atendidos os

6 ASSIS, Araken de. Processo Civil brasileiro. São Paulo: Revista dos Tribunais, 2015.

7 "Art. 355. O juiz julgará antecipadamente o pedido, proferindo sentença com resolução de mérito, quando: I - não houver necessidade de produção de outras provas; II - o réu for revel, ocorrer o efeito previsto no art. 344 e não houver requerimento de prova, na forma do art. 349." 
requisitos, o juiz intimará o autor para que promova o aditamento da inicial, nos termos do art. 303, decisão em que poderá determinar a complementação da causa de pedir, a confirmação do pedido de tutela antecipada ou a juntada de novos documentos, a fim de auxiliar em sua cognição, no prazo de 15 dias ou mais, caso entenda necessário.

Nesse cenário, cabe ainda frisar que, quando a tutela satisfativa é deferida em caráter antecedente e o réu, litisconsorte ou assistente queda-se inerte a impugná-la, ocorre o fenômeno denominado estabilização da tutela antecipada, em razão da extinção do processo sem resolução do mérito e permanência dos efeitos requeridos pelo autor até que a parte contrária ajuíze uma ação visando revisar, reformar ou invalidar a tutela concedida. O NCPC dispõe expressamente que não há formação de coisa julgada em tal hipótese, mas o fato é que, em casos assim, a tutela permanecerá vigente até que seja efetivamente reformada por decisão judicial posterior.

\subsection{Tutela de evidência}

Por fim, nos resta tecer alguns comentários acerca das peculiaridades da tutela de evidência. Ao contrário do que ocorre com as tutelas de urgência, para requerimento da tutela de evidência não é preciso demonstrar o perigo de dano ou risco ao resultado útil do processo, mas mostra-se imprescindível a demonstração de evidência do direito. Da mesma forma, não se permite o requerimento em caráter antecedente, mas na forma incidental, podendo ser formulada em petição avulsa ou na própria petição inicial.

Coube ao art. 311 no NCPC fixar as hipóteses de cabimento da tutela de evidência:

Art. 311. A tutela da evidência será concedida, independentemente da demonstração de perigo de dano ou de risco ao resultado útil do processo, quando:

I - ficar caracterizado o abuso do direito de defesa ou o manifesto propósito protelatório da parte;

II - as alegações de fato puderem ser comprovadas apenas documentalmente e houver tese firmada em julgamento de casos repetitivos ou em súmula vinculante;

III - se tratar de pedido reipersecutório fundado em prova documental adequada do contrato de depósito, caso em que será decretada a ordem de entrega do objeto custodiado, sob cominação de multa; 
IV - a petição inicial for instruída com prova documental suficiente dos fatos constitutivos do direito do autor, a que o réu não oponha prova capaz de gerar dúvida razoável.

Note-se que o inciso II traz por requisito não apenas a capacidade de a parte comprovar seu direito documentalmente, mas acrescenta, ainda, a necessidade de se demonstrar, outrossim, que a matéria debatida já foi objeto de julgamento favorável em casos repetitivos ou de súmula vinculante, o que não era exigido pelo revogado diploma legal quando se tratava de tutelas provisórias. Salienta-se, ainda, que não houve limitação aos precedentes do Supremo Tribunal Federal (STF), deixando a novel legislação espaço para que sejam utilizados enunciados vinculantes dos tribunais de justiça ou tribunais regionais federais, com fulcro nos art. 332, inciso IV, e 927, inciso $\mathrm{V}^{9}$ do NCPC.

A despeito de tais peculiaridades, o exame do art. 311 nos mostra, ao final, que apesar de parecer um novo instrumento de tutela, seus fundamentos já eram percebidos no $\mathrm{CPC} / 73$, quer seja no rito do mandado de segurança, cuja concessão da liminar exige a presença de direito líquido e certo e prova documental inequívoca, quer seja na possibilidade de concessão de tutela antecipada quando configurado abuso do direito de defesa ou manifesto propósito protelatório do réu, nos termos do art. 263, inciso II.

\section{CONSIDERAÇÕES FINAIS}

Feitas as considerações necessárias acerca das tutelas provisórias, deve ser respondida, então, a questão que dá origem ao presente artigo. Afinal, há ou não há base legal para a antecipação de garantia no NCPC?

Certamente há, e não poderia ser diferente, afinal, buscou o legislador no novo diploma legal sistematizar o que já existia no $\mathrm{CPC} / 73$, aperfeiçoando sua concessão e buscando maior efetividade da prestação jurisdicional pela consolidação e pela unificação jurisprudencial, e não restrição de direitos já garantidos aos jurisdicionados. O fato é que os fundamentos em que se apoiavam os contribuintes

8 "Art. 332. Nas causas que dispensem a fase instrutória, o juiz, independentemente da citação do réu, julgará liminarmente improcedente o pedido que contrariar: [...] IV - enunciado de súmula de tribunal de justiça sobre direito local."

9 “Art. 927. Os juízes e os tribunais observarão: [...] V - a orientação do plenário ou do órgão especial aos quais estiverem vinculados." 
para pleitear a medida acautelatória em debate sob a égide do CPC/73 continuam existindo: (i) fundado receio de dano; (ii) possibilidade de oferecimento de caução pela parte interessada; (iii) equiparação da caução oferecida pelo contribuinte à penhora antecipada que viabiliza a emissão de certidão de regularidade fiscal, nos termos do art. 206 do CTN; e (iv) necessidade de se tratar de forma isonômica os contribuintes, quer tenham eles débitos ajuizados ou não.

Mas qual seria então, dentro desse novo contexto, a medida adequada ao contribuinte para a antecipação da garantia a ser ofertada em futura execução fiscal? Parece-nos, com base no quanto analisado até o momento e tomando em conta também o histórico jurisprudencial da matéria, que a tutela cautelar antecedente é a medida mais adequada ao propósito em debate, devendo ser requerida com fulcro nas disposições do art. $300, \S 2^{\circ}$, para que seja concedida liminarmente.

Para alcançar tal conclusão, analisamos, inicialmente, o fundamento invocado para autorizar a concessão da tutela provisória requerida. No caso do contribuinte em limbo processual tributário, o que se pretende é apenas garantir os débitos inscritos em dívida ativa para que não obstem a emissão de CPEN, enquanto não ajuizada a respectiva ação de execução fiscal. Busca-se, portanto, tutela de natureza acautelatória, capaz de assegurar ao jurisdicionado seu direito, antecipando-se os efeitos que seriam obtidos com a penhora no executivo fiscal, ainda não materializado.

Ressalte-se que, não obstante a requisição de forma antecedente, já que não há pedido principal formulado para se requerer a tutela de modo incidental, o NCPC faculta ao autor a possibilidade de formular o pedido principal conjuntamente com o de tutela cautelar, afastando a necessidade de aditamento ou complementação da petição inicial. De todo modo, ainda que entenda o leitor pelo cabimento da tutela de urgência antecipada e não cautelar, dada a sutileza da diferença entre uma e outra, nenhum prejuízo experimentará o autor, em razão da fungibilidade expressa prevista no parágrafo único do art. 305.

Portanto, já concluindo este breve estudo, parece-nos que permanece o contribuinte amparado, agora pelas disposições do NCPC, para pleitear a antecipação da garantia de seus débitos, de forma a assegurar a emissão da certidão de regularidade fiscal e o consequente exercício regular de suas atividades empresariais. 
